\title{
EXPERIMENTAL SETUP FOR STUDYING THE CAPTURE OF SULFUR AND NITROGEN OXIDES FROM FLUE GASES
}

\author{
Andrey S. Sysolyatin ${ }^{1,}$, Sergey V. Kryukov ${ }^{1}$, Maxim A. Chemakin ${ }^{1}$, and Igor V. \\ Dvorovenko ${ }^{1}$ \\ ${ }^{1}$ Institute of Power Engineering, Kuzbass State Technical University named after T.F. Gorbachev, \\ 650000 Kemerovo, Russia
}

\begin{abstract}
The pilot unit is developed for adaptation of the absorptive mathematical model in a scrubber of the Venturi on a finding of factors of phase equilibrium by algorithm working off in the absorptive processes of extraction $\mathrm{SO} 2$ on water. The technique of work by test tests of trapping $\mathrm{CO} 2$ for water which have shown adequate work of a scrubber of the Venturi in the cascade with a spray separator-cyclone separator is completed.
\end{abstract}

\section{Introduction}

At the present stage of human development more than $850 \mathrm{mln} t$ of nitrogen oxides, 150 mln $t$ of sulfur dioxide, $310 \mathrm{mln} t$ of carbon monoxide, $250 \mathrm{mln} t$ of carbon dioxide, and 3 $\mathrm{mln} t$ of hydrocarbons are released into the atmosphere in the world annually [1].

Energy companies supply to the atmosphere more than $23 \%$ of emissions from all stationary sources in the Russian Federation. And among these emissions, nitrogen oxides accounts for about $97-98 \%$ (vol.), and others are sulfur oxides and various substances. Among sulfur oxides, $\mathrm{SO}_{2}$ accounts for only $97-98 \%$, and the rest is the share of $\mathrm{SO}_{3}$ [2].

Nitrogen and sulfur oxides in the flue gases are the toxic substances, and in the case of their mixing with air moisture, they form acids, which, falling to the earth in the form of socalled acid rains, damage the farmlands, destroy engineering structures, and harm human health and all living things on Earth.

Therefore, a very important problem is development of the technological processes for cleaning the gas emissions of HPP from harmful gas components and fine solid suspensions.

The main methods used for cleaning gas emissions are absorption, adsorption and catalytic technique; each of them has its own advantages and disadvantages.

Industrial gases are emitted into the atmosphere in large quantities, exceeding in some cases, a million cubic meters per hour. The current cleaning devices cannot be used due to their low capacity by gas. The only types of devices meeting the given cleaning

\footnotetext{
Corresponding author: teu.pmahp@rambler.ru
} 
requirements are the hollow vortex apparatuses with high capacity, small size and low flow resistance, such as the Venturi scrubbers (tubes) and hollow spray-type absorbers [3-5].

Turbulent Venturi scrubbers are one of the most effective devices for wet gas cleaning. The main advantages of Venturi scrubbers are easy manufacturing, installation and maintenance, small sizes and high efficiency of fine particles catching [6]. In devices of this type, cooling, humidification and absorption of gases can be carried out simultaneously with purification.

Quite a long time, the following absorbents are commonly used in practice for cleaning from sulfur oxides: water and water solutions of: $\mathrm{Na}_{2} \mathrm{SO}_{3}$ (18-25\%), $\mathrm{NH}_{4} \mathrm{OH}$ (5-15\%), $\mathrm{Ca}(\mathrm{OH})_{2}, \mathrm{Na}_{2} \mathrm{CO}_{3}, \mathrm{NaOH}(15-20 \%), \mathrm{KOH},\left(\mathrm{NH}_{4}\right)_{2} \mathrm{SO}_{3}(15-20 \%),\left(\mathrm{NH}_{2}\right)_{2} \mathrm{CO}, \mathrm{ZnSO}_{4}, \mathrm{~K}_{2} \mathrm{CO}_{3}$, etc. $[4,7]$.

Recently, to improve the efficiency of flue gas cleaning, the methods of selective noncatalytic reduction (SNCR) [8] and $\mathrm{SO}_{2}$ absorption by molten eutectic mixture of alkali metal carbonates (lithium, sodium and potassium) [9] are used in practice.

\section{Experimental setup}

The purpose of this work is creation of the experimental, rather uniform setup for studying the effectiveness of catching sulfur oxides, nitrogen oxides and mercury vapors using the most active absorbent-absorbed substance system, whose absorptive capacity is higher than that of the currently existing absorption pairs, and water consumption is reduced.

The schematic diagram of experimental setup for studying the efficiency of capturing sulfur and nitrogen oxides and mercury vapors by different absorbents, based on [10], is shown in fig. 1.

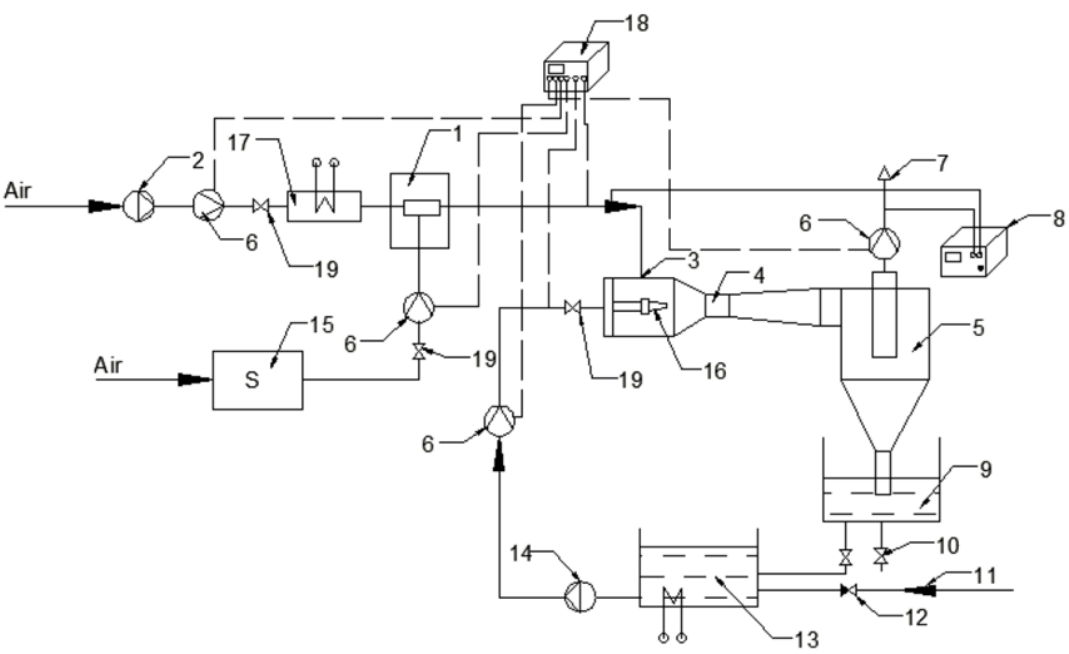

Fig. 1. Scheme of experimental setup: 1 - injector; 2 - air blower; 3 - introduction of gasair mixture into scrubber; 4 - Venturi scrubber; 5 - cyclone; 6 - flow meter; 7 - output of cleaned gas mixture; 8 - gas analyzer; 9 - tank; 10 - valve; 11 - inlet of make-up absorbent; 12 - check valve; 13 - tank for absorbent; 14 - pump; 15 - furnace; 16 - nozzle; 17 - air heater; 18 - analogue-digital system for control and measuring; 19 - regulation valve.

An experimental setup consists of Venturi scrubber 4, cyclone 5, furnace 15, blower, pump, tanks, control devices, devices for measuring the flow rates and temperatures of 
gases and water, and concentrations of gases in air. Air is supplied by the blower into injector 1, where sulfur oxides or other gases from the furnace are injected; then, the formed gas mixture enters the Venturi scrubber, where oxides are absorbed by water with various additives. Then, gas-water mixture passes through the cyclone, where it is separated into the gaseous and water components, water is discharged from the cyclone from the bottom into the receiving tank, and gases are released from the top into the atmosphere. Gas and water flow rates are measured at the scrubber inlet, gas concentrations are measured in air at the scrubber inlet and gas outlet from the cyclone. The gas and water flow rates can be changed by the control valves, which allow research at various concentrations of impurities in air and different water flow rates in a wide range of determining parameters. The operation and equilibrium lines can be plotted using data obtained, which can be also used to evaluate the effectiveness of capturing and determine the most optimal operation regime of the setup.

\section{Result and discussion}

At the initial stage of research, there is the task to adapt the absorption mathematical model [11] for the Venturi scrubber at the sorption process in the framework of solving the inverse problem of finding the coefficients of phase equilibrium, fulfilling the algorithm for $\mathrm{SO}_{2}$ recovery on water.

In this connection, the tests on performance of the experimental setup on $\mathrm{CO}_{2}$ absorption by water were carried out. The tests were carried out on the setup for the following constant parameters: absorbent temperature (water) of $6^{\circ} \mathrm{C}$; absorbed substance temperature of $22^{\circ} \mathrm{C}$; inert gas flow of $0.01697 \mathrm{~kg} / \mathrm{s}$; gas velocity in Venturi scrubber throat of $44 \mathrm{~m} / \mathrm{s}$. The amount of absorbed component $M$ vs. irrigation density $q$ is shown in fig. 2 .

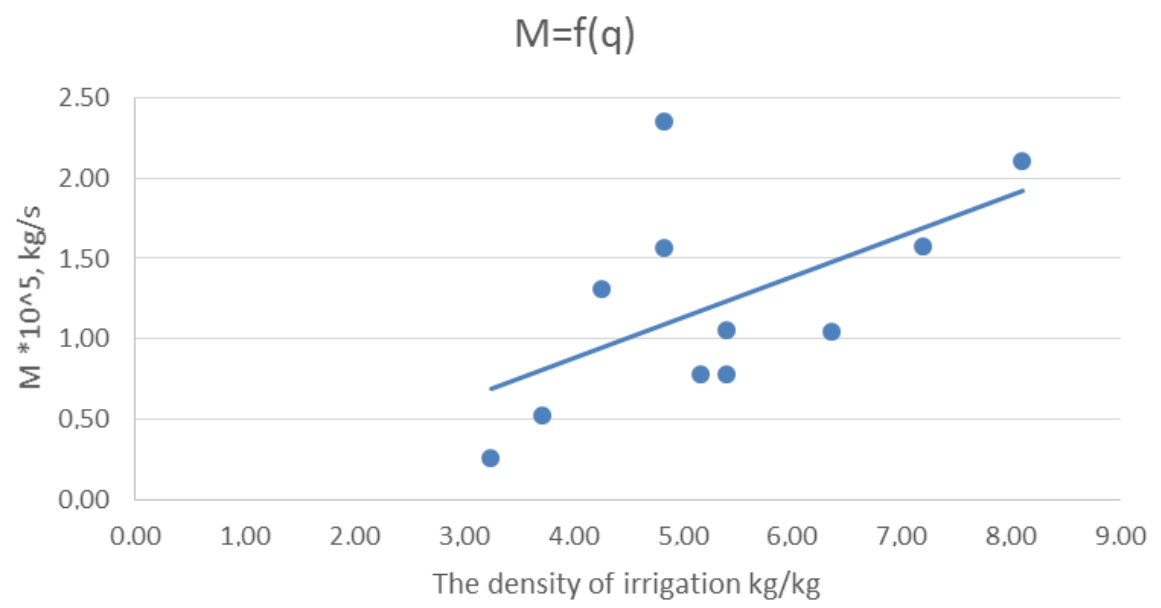

Fig. 2. The amount of absorbed component $\mathrm{CO}_{2}$ from air-gaz mix vs. irrigation density.

\section{Conclusion}

The experimental setup for studying the capture of sulfur oxides, nitrogen oxides and mercury vapors was developed;

The primary experiments on capturing carbon dioxide were carried out; they showed the possibility of using the setup for adaptation of chemisorption processes. 


\section{Acknowledgments}

The work was financially supported by the Russian Ministry of Education and Science $n$ the framework of the Federal target program "Research and development in priority directions of development of scientific-technological complex of Russia for 2014-2020”, according to Agreement No.14.583.21.0004 about the subsidies on July 16, 2014. The unique identifier of research (project) is RFMEFI58314X0004.

\section{References}

1. S.E. Belikov, Integrated development of the methods for reducing nitrogen oxide emissions of thermal power plants by optimizing the combustion process and methods of fuel combustion (Moscow, 2006)

2. E.R. Zvereva, T.M. Farakhov, A.R. Iskhakov, KSEU Bul. 8 (2011)

3. A. V. Dmitriev, Cleaning gas emissions of HPP, working on liquid and solid fuel, in vortex apparatuses (Kazan, 2006)

4. Yu. V. Zykin, Development of resource-saving technology of wet scrubbing of HPP flue gases from ash (Kazan, 2003)

5. A. S. Kazaryan, Complex cleaning of flue gases of heat generating installations (Rostov-on-Don, 2005)

6. V. M. Ramm, Absorption of gases (Khimiya, Moscow, 1976)

7. I.A. Volchin, S.V. Mezin, L.N. Rudenko, A.A. Yasinetskiy, Energ. 6 (2015)

8. O.N. Kulish, S.A. Kuzhevatov, I.Sh. Gleizer, M.N. Orlova, E.V. Ivanova, A.M. Zykov, O.N. Bragina, K.I. Kilchin, and S.N. Anichkov, Energ. 4 (2014)

9. N.K. Dosmukhamedov, V.A. Kaplan, E.E. Zholdasbay, D.N. Dosmukhamedov, I. Lyubomirskiy, Coal 8 (2015)

10. A.I. Kalachev, TEK. Str. Dev. 39 (2015)

11. M. I. Shilyaev, E. M. Khromova, A. R. Bogomolov, S. N. Shirokova, Izv. Vuz. Str. 3 (2015) 